\section{Focus on psychiatry in Poland}

\author{
Past and present
}

MAREK BALICKI, STEFAN LEDER and ANDRZEJ PIOTROWSKI

\section{POLISH MENTAL HEALTH CARE SYSTEM}

The German occupation of Poland in 1939 was accompanied by the destruction of the existing medical system, and the first victims of the Nazi terror were psychiatric patients in hospitals - around 15000 were exterminated and about 10000 died as a result of malnourishment.

When the rebuilding of the country and its health care system began in 1945, psychiatry had a low priority. Although most in-patient institutions were soon re-established and many large mental hospitals existed in the former German regions, it was impossible to ensure adequate care and treatment of patients because of insufficient numbers of psychiatrists: only 80-120 were available to take care of persons with mental disorders. In the early 1950s a pronounced deficit of psychiatric beds was recorded in central Poland and this contributed to the regular transfer of psychiatric patients to hospitals in western Poland, where some minimal security, medical treatment and care could be assured. But the negative effects of this solution were soon observed and continue to be felt. The continuous weakening of family ties and relationships and the large numbers of patients cared for by too few staff without

Table I Statistical information for Poland

\begin{tabular}{|c|c|}
\hline Population & 38.6 million \\
\hline \multicolumn{2}{|l|}{ Regional distribution of population } \\
\hline Urban areas & $62 \%$ \\
\hline Rural areas & $38 \%$ \\
\hline Population aged over 65 & $12 \%$ \\
\hline Unemployment rate & $12 \%$ \\
\hline Agricultural sector employment & $27 \%$ \\
\hline Administrative division & 16 provinces \\
\hline \multicolumn{2}{|l|}{ GDP per capita, as \% of GDP } \\
\hline for EU countries & $35 \%$ \\
\hline
\end{tabular}

adequate active rehabilitation measures contributed to the effect of long-term hospitalisation and the chronicity of disorders.

An important positive factor for the development of psychiatric services was the rapid establishment of medical faculties in seven universities. Students received free training to become physicians and many of them chose to specialise in psychiatry. The most important event in setting up a comprehensive, free general health care system, including in- and out-patient psychiatric services, was the acceptance of a special Act by Parliament in 1952. This facilitated the development of new concepts and treatment modalities and methods and their introduction into practice.

Sectorisation of mental hospitals and sub-sectorisation of their wards (see below) was introduced in 1968. This resulted in a 'rotating door policy' and a reduction in the number of in-patient beds by about $20 \%$ between 1970 and 1990. This decrease was possible thanks to extension of the existing network of out-patient clinics, the organisation of day hospitals and a substantial rise in the number of psychiatric wards in general hospitals.

At this time, the existing predominantly medical model of treatment of mental disorders was supplemented by the introduction of the therapeutic community ideology in mental hospitals, acceptance of community psychiatry principles in the organisation of services, and the development of various kinds of psychotherapeutic technique applied to patients with neurotic and other disorders. Goffman and Laing were frequently quoted authors.

These developments and activities were initiated and coordinated by the Institute of Psychiatry and Neurology in Warsaw and supported by university departments of psychiatry and the Polish Psychiatric Association. The Institute, an adviser to the Ministry of Health on the organisation of mental health care services, introduced a standardised psychiatric documentation system. Annual statistical data and their conclusions were published and presented to the Ministry by psychiatrists. A review of the state of the psychiatric care system and a programme of further development, taking into account probable changes in the morbidity rate and actual and future needs, was developed during the period 1971-1975 also presented to the Ministry. From the second half of the 1970s, however, this ambitious programme was undermined and endangered by the acceleration and deepening of a broad socio-economic and financial crisis, which had a strong impact on the medical health care system and its psychiatric sector.

\section{PSYCHIATRIC STAFF}

\section{Psychiatrists}

There are currently medical faculties in 11 universities in Poland. Having completed 6 years of study and 18 months of internship, 6 weeks of which must be spent in psychiatric services, it is possible to enter a speciality programme in psychiatry (residency).

Since 1999 psychiatry has been recognised as a major speciality, with child and adolescent psychiatry as a sub-speciality. The programme of residency in psychiatry consists of 5 years of training, after which the resident must pass a national examination to obtain a certificate of general psychiatry. To become a fully qualified child and adolescent psychiatrist one has to undergo 2 additional years of training. The Polish programme follows the main assumptions of the programme elaborated by the Psychiatric Section of the Union Européenne des Médicins Spécialistes. Residents in psychiatry can also enter a special 3-year programme, the goal of which is to obtain a licence in psychotherapy granted by the Section of Psychotherapy of the Polish Psychiatric Association.

A system of continuing medical education (CME) has existed since 1970; refresher courses for specialists in psychiatry are organised by university chairs of psychiatry and the Institute of Psychiatry and Neurology. Recently, a system of credit points assigned for attendance at scientific and professional meetings was introduced. 


\section{Psychologists}

There are eight university faculties of psychology. Until 1999 clinical psychology was recognised as a non-medical speciality applicable to medical practice. Since 1999, however, clinical psychology does not appear on the list of basic medical specialities projected by the Ministry of Health.

\section{Nurses}

After finishing nursing school (college level) it is possible to enter one of two university faculties of nursing to study for a Master's degree. Registered nurses working in psychiatry may enter a special programme leading to the qualification of psychiatric nurse.

\section{Social workers}

Social workers have a college education and many continue studies to obtain a Master's in sociology or applied social sciences.

\section{Staff resources}

The total number of psychiatrists of the first and second grade speciality ( 3 and 5 years of specialisation, respectively) is steadily growing: 1919 in 1992 and 2170 in 1995 (for 1995 this equates to $0.6 /$ 10000 general population). In 1995 psychiatrists constituted $3.1 \%$ of all medical specialists.

The number of psychologists working in all kinds of psychiatric service is about 1500. Many of them have obtained a licence in psychotherapy. Most psychologists practise psychotherapy within public psychiatric services, although some work privately. In addition, quite a number are involved in psychosocial and rehabilitation programmes carried out within psychiatric services.

A total of 7325 registered nurses are employed in in-patient services $(1 / 1.47$ beds in 1996). The number of registered nurses working in extramural services is not known. However, at least one nurse is employed in every out-patient clinic.

It is not known how many social workers are employed in psychiatric services, but a substantial number work with the mentally ill as employees of social care centres at a local community level.
Table 2 In-patient services in Poland, 1997

\begin{tabular}{lr}
\hline Type of facility & No. of beds' \\
\hline Mental hospital & 22322 \\
Psychiatric ward within general hospital setting & 3742 \\
Ward for alcoholics (detoxification, rehabilitation) & 3197 \\
Centre for addicts other than alcoholics & 1285 \\
Child and adolescent & 1367 \\
Total & 31913 \\
\hline
\end{tabular}

I. Distributed among 50 psychiatric hospitals, 56 psychiatric wards within general hospitals, 20 wards for alcohol detoxification/rehabilitation and 37 centres for treatment of non-alcohol substance misuse.

\section{PSYCHIATRIC SERVICES}

\section{In-patient services}

In 1997 there were 31913 psychiatric beds throughout Poland (Table 1). Data indicate that 152504 admissions took place in that year; 65817 persons (43\% of admissions) were admitted for the first time and some were admitted more than once. There is quite a large population of long-term patients $(27.2 \%$ of all hospitalised on 31
December, 1995 stayed longer than 1 year). Mental hospitals house $83 \%$ of all psychiatric beds and $34 \%$ of the total number of beds are in the 11 largest hospitals (over 900 beds) (1997 data). Only $11.7 \%$ of the beds are located in psychiatric wards of general hospitals. Between 1970 and 1996 the average number of patients staying in hospitals (counted at the end of the year) fell from 39000 to 25000 . In the 1990 s the number of people with mental disorders
Table 3 Diagnoses of patients in mental health facilities in Poland: selected rates per 100000 population

\begin{tabular}{|c|c|c|c|}
\hline Diagnosis & 1985 & 1990 & 1995 \\
\hline \multicolumn{4}{|l|}{ All out-patients } \\
\hline Total, all mental disorders & 1559.7 & 1628.9 & 1884.8 \\
\hline Alcohol-related disorders & 241.6 & 260.9 & 274.1 \\
\hline Psychoses' & 433.7 & 466.4 & 565.8 \\
\hline of which affective psychoses & 86.5 & 104.8 & 148.3 \\
\hline Non-psychotic disorders' & 820.4 & 837.8 & 971.6 \\
\hline of which neurotic disorders & 554.4 & 568.8 & 667.2 \\
\hline Learning disability & 64.0 & 63.8 & 73.4 \\
\hline \multicolumn{4}{|l|}{ New out-patients } \\
\hline Total, all mental disorders & 454.7 & 443.9 & 517.6 \\
\hline Alcohol-related disorders & 91.2 & 89.6 & 101.0 \\
\hline Psychoses' & 61.4 & 63.5 & 85.0 \\
\hline of which affective psychoses & 14.0 & 16.7 & 27.7 \\
\hline Non-psychotic disorders ${ }^{\prime}$ & 283.0 & 275.1 & 312.0 \\
\hline of which neurotic disorders & 193.7 & 193.0 & 219.0 \\
\hline Learning disability & 39.1 & 15.7 & 19.5 \\
\hline \multicolumn{4}{|l|}{ New in-patients } \\
\hline Total, all mental disorders & 136.0 & 129.4 & 147.2 \\
\hline Alcohol-related disorders & 39.1 & 45.0 & 58.8 \\
\hline of which alcohol psychoses & 11.3 & 13.4 & 15.0 \\
\hline Psychoses' & 47.4 & 43.1 & 45.1 \\
\hline of which affective psychoses & 7.3 & 7.7 & 11.2 \\
\hline Non-psychotic disorders' & 46.1 & 38.4 & 40.5 \\
\hline of which neurotic disorders & 16.6 & 13.4 & 13.8 \\
\hline Learning disability & 3.4 & 2.8 & 2.8 \\
\hline
\end{tabular}

I. Excluding alcohol-related disorders. 
Table 4 Selected psychosocial data for Poland

\begin{tabular}{lrrr}
\hline & 1985 & 1990 & 1995 \\
\hline $\begin{array}{l}\text { Deaths per 100 000 population } \\
\text { Suicide and self-harm (causing death) per } \\
\quad 100000 \text { population }\end{array}$ & 1032.1 & 1024.0 & 1000.5 \\
$\begin{array}{l}\text { Recorded crimes } \\
\text { of which against life and health }\end{array}$ & 544361 & 13.0 & 14.3 \\
$\begin{array}{l}\text { Suicides registered by police } \\
\text { Registered unemploymed persons }\end{array}$ & 16967 & 15509 & 974941 \\
Retired and pensioners (at beginning of year) & 4517 & 3841 & 51235 \\
\hline
\end{tabular}

I. In completed preparatory proceedings.

increased by $19 \%$ and the incidence increased by $20 \%$ (during the 1990-1997 period). The highest degree of growth is represented by depression, schizophrenia and alcoholic psychoses. The percentage of the total number of people with mental disorders treated in hospitals has decreased by $3.7 \%$, but the percentage of people treated for the first time has increased by $12 \%$. People addicted to alcohol account for $30 \%$ of patients in psychiatric wards and hospitals.

Mental hospitals have to deal with a difficult problem imposed by the penal code. People identified by the court as incapable are placed in mental hospitals, which are obliged to treat them under special security measures. Particularly dangerous patients (about 400 throughout the country) are expected to be transferred to special security wards.

\section{Day hospitals}

There are 110 day hospitals (including 14 for patients with neurotic disorders and 13 for children and adolescents) with 2466 places. The majority of admissions are of patients with psychoses coming directly from the community (most often as an alternative to in-patient admission); other patients are transferred from inpatient wards to continue treatment and rehabilitation.

\section{Out-patient psychiatric clinics}

The network of out-patient clinics is quite well developed. However, only $71 \%$ of the 594 operating in 1997 (including clinics for children and adolescents) had a fulltime psychiatrist and were open every day. In 1997 there were 664148 patients (one or more visit per year) registered. Clinics are being criticised for a tendency to see the patient mostly 'at the office', but the number of home visits by psychiatrists is growing (111000 visits took place in 1995). Social workers and community psychiatric nurses in some centres are also more active. As far as patients with psychoses are concerned, it is difficult to preserve continuity of care, owing to the often considerable distance between clinics and sectorised psychiatric wards and the different management of the ward treatment team and the out-patient treatment team (the latter operates within the general health system administration).

\section{Out-patient clinics for alcoholism}

Since alcoholism has been recognised for many years as one of the most important social problems in Poland, with serious medical consequences, a special network of in-patient facilities and out-patient clinics has been created within the system of mental and general health care. In 1997 there were 425 out-patient clinics for alcoholism; 112900 patients presented at these clinics one or more times during the year. There are approximately 1200 Alcoholics Anonymous (AA) groups in the country (the number has been growing rapidly since the late 1980 s), and about 400 Alanon and 100 Alateen groups. The importance of the AA movement is recognised from the social as well as medical point of view.

\section{Out-patient clinics for drug addiction}

The number of specialist out-patient clinics for treating drug addiction is relatively small. In 1996 there were 33 such facilities (28 in 1990) treating 5835 patients $(2800$ in 1990).

\section{PSYCHOTHERAPY}

During the first years after the Second World War the main task was the education of medical staff and the organisation of the primary psychiatric care system, and therefore the issue of the place and role of psychotherapeutic treatment of patients with mental disorders was not a priority. In educational programmes in psychiatry, for both students and postgraduates, psychotherapy was inadequately addressed. The presentation of different theoretical schools was superficial and often dictated by ideological prejudices. This hampered pluralistic debates. Psychotherapeutic treatment was based on a simplistic version of Pavlovian views and it accelerated the transformation of the Institute of Mental Hygiene into the Central Out-Patient Centre of Psychic Health. In the second half of the 1950s three main centres of psychotherapy (two in Warsaw, one in Krakow) became the influential organisers, teachers and promoters of the spreading and broadening implementation of psychotherapeutic treatments in mental hospitals and out-patient facilities, which then numbered about 60 .

These three centres proposed different models. The first was based on social learning and group dynamics, and developed an integrative approach toward the treatment of patients with neurotic, personality and psychosomatic disorders in the framework of a therapeutic community in in- and out-patient facilities and institutions. The second model employed mainly group therapy combined with occupational therapy based on a psychodynamic approach. The third group propagated eclectic psychotherapeutic approaches, including hypnosis and relaxation methods, and group sessions in psychosomatic and psychiatric departments based on psychodynamic concepts and, later, on the family therapy model. At this time the Scientific Section of Psychotherapy was established in the Polish Psychiatric Association (1961). New in-patient facilities for people with neurotic disorders were established in Wroclaw, Lódz and Poznań. These three centres cooperated in the organisation of training and teaching activities with the Scientific Section of Psychotherapy and its working groups for hypnosis, group therapy, research, music therapy and behavioural therapy. These organisational and educational activities were enriched by the use of foreign publications 
(Kratochvil's books on different psychotherapeutic issues were of particular importance) and by visits of prominent psychotherapists, including Frankl, Rogers, Ploeger, Mowrer, Meyer and Frank. Between 1962 and 1989 about 300 psychiatrists and psychologists participated in 2-, 4- and 6-week courses in psychotherapy. In 1973 a comprehensive training programme was introduced, in which the participants had the opportunity to learn about the various theoretical psychotherapeutic schools and to stay in different psychotherapeutic centres, to participate as residents and to be trained as 'experts', Balint group conductors and certified supervisors.

The Act governing the award of a licence in psychotherapy and the unified programme content were approved in 1991. By 1999 about 280 people had received their licences and the Section of Psychotherapy had about 500 members; the Balint Society had awarded Balint certificates to around 50 people.

\section{HEALTH CARE BEFORE HEALTH INSURANCE}

The transformation of the Polish political system began in 1989 facilitated the dynamic development of non-government organisations and civic initiatives. The process of a rapidly increasing economic and social differentiation, however, has increased the number of social problems. The economic situation of a substantial part of society has deteriorated. Some regions continue to have high unemployment, and long-term poverty occurs, which transforms itself into the phenomena of marginalisation and inherited poverty. We observe an increased crime rate, consumption of psychoactive substances (alcohol and others) and a growing number of suicides. Limited access to the health care services, education, culture and leisure is a new element of social inequality.

Before the introduction of health insurance nearly $100 \%$ of the population was entitled to free health care in public facilities. Health care was mainly provided by a public sector financed from the central budget and run by governmental administration. In more recent years, the private sector, financed directly by patients, has been rapidly developing. A few thousand private facilities have been established and nearly 30000 physicians have their own private practices.

The Ministry of Health and Social Welfare was responsible for defining health policy and public health issues, planning the health care budget, and supervising health care and the provision of highly specialist care in 'subordinated' hospitals. The 49 provinces, and more than 400 integrated health care complexes ( $\mathrm{ZOZ})$ and provincial hospitals subordinated to them, were responsible for the provision of public, easily accessible primary care and specialist health care for the population. Recently, a number of integrated health care complexes were divided into out-patient treatment centres and hospitals, each with their own separate finances and administration. This separation has hampered continuity of care of the individual patient. Some of the facilities, mainly the out-patient centres, were taken over by local governments (municipalities).

In 1991 broad access to free drugs was abandoned and a limited list of reimbursable drugs was introduced (about one-fifth of all the drugs registered in Poland). Certain drugs are still given free of charge for some chronic diseases, including psychiatric illnesses.

Among the activities preceding the introduction of health insurance, it is worth highlighting the National Health Programme (NPZ) introduced in 1990, which is a Polish version of the World Health Organization's 'Health for All'. In 1991, an important year for the process of reform, the Health Care Institution Act was passed. The provisions within the Act were to enable the introduction of elements of an internal market. In 1992 the specialisation of 'family physician' was established and postgraduate education of family physicians began. The goal of reforms is, inter alia, to replace the current model of primary health care based on the work of a team of specialists (internist, paediatrician, gynaecologist) by a network of general practitioners prepared to provide comprehensive and continuous care.

At the same time, as a result of a reduction in state health care expenditure, the development of the private sector and the expansion of a 'grey market' (unregistered businesses), the share of public funds in total health care expenditure has fallen from about $90 \%$ in the 1980 s to $60 \%$ or less now. The crisis in the public provision of services and the inevitable related inequalities in access to health care confirm this finding.

\section{MENTAL HEALTH CARE AND OTHER SOCIAL SUPPORT BEFORE HEALTH INSURANCE}

Health care for people with mental disorders is maintained within the scope of primary health care and specialist care, mainly in mental health care facilities.

During the past 25 years we have witnessed a positive trend concerning a substantial reduction in the number of beds (especially in large hospitals) and improved accessibility as a result of a more even distribution thanks to the establishment of psychiatric wards in general hospitals. The sub-sectorisation of mental hospitals in 1968 divided the operational area of the hospital into smaller territories (sub-sectors) served by individual departments of the hospital, cooperating with the mental health out-patient clinics appropriate for the given sub-sector. The sub-sectorisation contributed to constraining the increase in the number of patients in hospitals, a substantial reduction in the number of hospital beds and the elimination or reduction in size of wards for chronically ill and disturbed patients as well as provision of in-hospital continuity care.

The Social Welfare Service System, reformed at the beginning of the 1990s, plays an increasingly important role in serving people with mental disorders. Gradually more places are becoming available in nursing homes for chronically ill patients and for children and adults with learning difficulties. Between 1970 and 1995 the number of such homes increased from 208 (19000 people) to 367 (36500 people). According to the Mental Health Act of 1994 the social welfare agencies are organising social support for people who, owing to mental illness or learning difficulties, face serious problems in their daily life, especially with interpersonal relations, education, employment and welfare issues. The two organisational forms of social support consist of specialist community care services delivered in the patient's home and social care day centres. By early 1998, about 3 years after the Act came into force, we already had 184 social care day centres providing services to about 5500 people with mental illnesses and 
learning difficulties. Specialist community care provided on an individual basis, mostly by psychiatric nurses and social workers in the patient's place of residence, is increasingly widespread. A substantial part of the social support services is provided by non-governmental organisations commissioned by the social welfare services. Burdening the social welfare services with the obligation to organise social support for people with mental illnesses has resulted in the dynamic development of these services, which in turn has substantially improved the situation of patients. This has become particularly important in light of the decrease in health care expenditure in the 1990s, including the expenditure on mental health care.

\section{REHABILITATION}

Before transformation, there were about 400 sheltered workshops oriented toward non-profit-making employment of people with disabilities. The market economy reduced the number of jobs in these workshops by about $50 \%$. More than 10000 people currently work in them, but they are expected to meet market-oriented standards of productivity. Only a small number of people with psychoses are among them.

In 1991 the State Fund for Rehabilitation of Disabled Persons was established. This resulted in the organisation of occupational therapy workshops. Among others, people with psychoses who can no longer work in their own profession are trained there to learn new skills. However, the situation of the labour market makes it hard for them to secure a job suitable for their new skills.

\section{MENTAL HEALTH PROGRAMME AND MENTAL HEALTH ACT}

In the mid-1990s two events took place that were important for the future of Polish psychiatry: the introduction of the Mental Health Programme and the passing of the Mental Health Act.

The Mental Health Programme was elaborated in the Institute of Psychiatry and Neurology by a committee directed by Stanislaw Dabrowski and was accepted by the Minister of Health in 1994.
The passing of the Mental Health Act by Parliament in 1994 was the most important event in the history of Polish psychiatry in the 1990s. Before this, Poland had no statutory regulation of involuntary admission to mental hospitals. The instructions of the Minister of Health of 1952 regarding admission and discharge of patients to and from mental hospitals did not meet the minimum international standards and did not provide institutional protection for mentally disordered patients. In addition, the lack of clear statutory regulations of the rights of the mental hospital patients gave rise to numerous irregularities. Work on the Act lasted several decades. In the 1970s an interesting public debate took place in the media concerning the project established on the initiative of the Polish Psychiatric Association. The debate revealed a substantial group of opponents to the idea of including the courts in the process of controlling decisions made by psychiatrists. Along with a rejection of widely presented paternalistic attitudes there was a justified lack of trust in the institutions of the authorities and in the independence of the courts. It is important to mention at this point that in Poland psychiatry was not used for political purposes. The attitude of Polish psychiatrists played a decisive role in this respect. Ratification of the European Convention for the Protection of Human Rights and Fundamental Freedoms by Poland in 1992 was an important incentive.

The Mental Health Act came into force in January 1995, thus filling a significant gap in the Polish legal system. It covers a wide range of mental health protection issues. Three major groups of problems are subject to the regulation. First, relating to the promotion of mental health and prevention of mental disorders, as well as the shaping of appropriate social attitudes towards people with mental disorders, counteracting discrimination. Second, the provision of comprehensive and accessible mental health care and other forms of care and assistance for people with mental disorders under the model of community mental health care and social welfare. Third, the protection of the civil rights of people with mental disorders, in particular definition of the guarantee of the rights of people admitted to and treated in hospitals without their consent.

It is worth mentioning three issues resulting from the Act. The first concerns the appointment of the Mental Health
Promotion Issues Council by the Minister of Health in January 1997. The Council is composed of representatives of various disciplines and a few ministries (health, labour and social policy, education, justice, and internal affairs). The deputy director of the Institute of Psychiatry and Neurology is the chairman of the Council.

The second issue concerns the Target Network of Public Psychiatric Health Care Facilities. It was assumed that this document would substantially contribute to the development of the psychiatric care system in Poland and especially to levelling out territorial differences and improving accessibility. Its full implementation is to be completed by 2005 . However, after the most recent radical reform of public administration it seems necessary to work out a new approach and adapt the document not only to the new territorial division of the country, but also to the changed legal and political conditions.

The third issue concerns the statutory regulation of the involuntary proceedings, which form a central component of the Act. Two modes of involuntary admissions to mental hospitals were introduced: emergency hospitalisation and non-emergency hospitalisation. Under emergency involuntary hospitalisation, the mentally ill patient can be admitted to hospital if he/she poses direct threat to his/her own life or to the life or health of others. The psychiatrist takes the decision on admission and then the decision is subject to court supervision. Under the non-emergency mode, the mentally ill patient can be admitted to hospital solely on the basis of a prior legally binding court verdict at the request of a family member or social welfare institution. This concerns the situation when not admitting a patient could cause considerable deterioration of that person's mental health or when the patient is incapable of self-sufficiency in satisfying his/her basic vital needs. The Act also contains provisions regulating the use of physical restraint. The Act envisages a clear system of judicial-procedural, judicial-supervisory and administrative-medical guarantees in order to protect the rights of people with mental disorders who are subject to compulsory proceedings. Despite the fact that the implementation of the Act has met with and still meets with a number of barriers and difficulties, it has substantially influenced the improvement of the enforcement of human rights in mental health care facilities and enhanced the 
independence of people with mental disorders.

The Act of 1982, on Bringing up in Sobriety and Counteracting Alcoholism, foresees the possibility of imposing an obligation to submit to treatment on a person considered to be alcohol dependent by a psychiatrist or psychologist presented to the court, if information gathered for the court confirms socially unacceptable behaviour. The court can oblige the person to be treated on an out-patient basis or - if that treatment is ineffective - on an inpatient basis for a period not longer than 3 months within the following 3 years.

The Law on Prevention of Addiction, regulating problems connected with illegal production, smuggling and trade of illicit drugs, gives judges the option of enforcing involuntary treatment.

The Penal Code of 1997 includes a regulation concerning an incapable person committing criminal acts being admitted to hospital for treatment and supervision under special security measures.

\section{AFTER THE 1999 REFORMS}

In 1999 two reforms came into force that radically changed the organisation and financing of the public health care system. In the self-government reform a three-tier division, comprising the previous selfgoverning municipalities (2500), selfgoverning counties (370) and regions (16), replaced the previous two tiers of administration (about 2500 self-governing municipalities and 49 government provinces). Facilities previously subordinated to local governmental administration have been transferred to self-governing county authorities (primary health care and health care centres) and self-governing authorities of the new provinces (specialist hospitals). Mental health out-patient clinics and some psychiatric wards in general hospitals have become the responsibility of the counties. The government administration in the new regions has very limited power with regard to health care. At the beginning of 1999 public authorities ceased to function as purchasers, and this function was taken over by the newly established Health Insurance Funds.

This links to the second major reform introducing universal health insurance. The core of the changes is the separation of the function of the purchaser and provider of services. The 16 regional health insurance funds have taken over the function of the purchaser. The self-governing authorities of the provinces will maintain supervision of the health insurance funds. Membership of a health insurance fund is compulsory, with a compulsory, taxdeductible premium of $7.5 \%$ of personal income. Funds sign contracts for provision of medical services with public (belonging to local government authorities) or private health care facilities and with private practitioners or group practices. Prior to the introduction of health insurance all public health care facilities had been transformed into independent entities (similar to trusts). The Ministry of Health will finance from the central budget only highly specialised procedures, excluding psychiatry. For psychiatric in-patients, the cost of a patient-day is the basis for the signed contract. (Patients do not pay themselves.) In specialised non-hospital care, the basis for the contract is the average cost of the procedure (visit). However, in primary health care a per capita system has been introduced.

\section{CURRENT SITUATION AND PERSPECTIVES}

The fact that three major reforms (health care, decentralisation of public administration, pension system) have been simultaneously introduced has been seen to be a cause of difficulties. Critics have also focused on unsatisfactory preparations, unsolved conflicts within the system, lack of information campaigns, non-cooperation (opposition) of doctors and other medical professionals and insufficient funding of the system.

Weaknesses of the new system are evident, but positive aspects are also emerging. It is possible to try to predict probable directions of change and propose action to prevent negative outcomes.

The tendency to reduce the state financing of health services remains. This was as high as $60 \%$ before the reforms and insurance funds now have serious problems in collecting previously planned sums. Independent economists estimate that the deficit of the insurance funds' budget will be as much as $14 \%$ of planned expenditure. Development of the private sector, the increase in payment for drugs and introduction of co-payment for some medical services in the public sector will result in a growth of out-of-pocket expenses on total health care expenditure. At the same time, there is a rapid increase in economic and social differentiation in society. These processes may result in a situation in which people with an average or low salary have worse access to the health services.

A reduction in medical professionals' wages in 1999 has been the cause of pauperisation of this group. First it harmed nurses and caused conflict and protests. Psychiatric health care depends on public finances more than other branches of health care. The system's decentralisation (insurance funds will be supervised at the provincial level) and reduction in expenditure may damage psychiatric services. The low social position, small voting power in political elections and traditional labelling of mentally ill persons can all influence priorities in health care to the detriment of the development of psychiatric services. There are examples of liquidation of some specialists facilities, such as limiting or closing down psychotherapy services in the public sector, that especially harm patients with neurotic disorders. Access to medical services in nursing homes has worsened. It seems that the current difficulties resulting from reduction of public financing will affect modernisation and development of mental health care.

Also, there are the effects of the new funding method: per visit for out-patients and per patient-day for in-patients. This leads to opportunistic attitudes, poorer quality of an increasing number of visits and, above all, to an increase in the total number of patient-days, causing overcrowded rooms in mental hospitals. It can also negatively affect deinstitutionalisation in psychiatry, resulting in prolonging hospital stays and preventing the reduction of beds in big mental hospitals. Another problem is the serious financial difficulties in large mental hospitals in western Poland, which have a higher than average number of long-term patients. Finally, there is the monopolistic position of the insurance funds and the fact that their employees lack experience, which has resulted in frequent errors in contracting services.

The reduction in financing and the new funding methods may threaten the psychosocial activities and rehabilitation of chronically mentally ill persons. In many places a deteriorating access to health services is observed. There are threats to 
the continuity of care (treatment and rehabilitation), which is crucial in community psychiatry. The new funding methods put the integrated facilities at a special disadvantage. There are limitations in access to emergency services: the total number of services has been reduced and new regulations introduced imposing a high payment for 'unnecessary' calls. These problems also affect psychiatric emergency cases. The situation is worse than before owing to the lack of crisis intervention centres and lack of evening and night cover by general practitioners.

The Health Insurance Act abolished the sectorisation of mental hospitals and psychiatric wards in general hospitals, which has been successful so far. Happily, the sub-sectorisation is still more or less functioning.

Limitations of Ministry of Health competencies, decentralisation of health policy and probable limitations of the Institute of Psychiatry and Neurology's influence on the new system are only some factors that may halt the process of transformation of psychiatric health care in Poland toward community-based care. This threat is more real now than at any time in the past decade.

The key policy documents governing the health care system (the Mental Health Act, the Mental Health Programme and the Target Network of Public Psychiatric Health Care Facilities) were passed under conditions of organisation and financing of the health care system and local administration different from those currently in force. It is almost certain that they cannot satisfy existing needs and considerable changes are unavoidable. There is a need for regulations guaranteeing equal access to health services. This could help to deliver continuity of health care and encourage the development of structures integrating various forms of services (in-patient and 'out of hospital' ones) at a county level.

Current funding of psychiatric facilities should be changed to a per capita rate to be paid to the health provider responsible for delivering or arranging for the delivery of all psychiatric services for a local population.

The Mental Health Programme could become a very useful instrument, on two conditions. First, it should be more operational and second, resources for the programme should be separated from the national budget. Very soon neither the insurance funds nor the local authorities will have enough funds. The Target Network of Facilities has become completely out of date as the new system of national and local administration has been introduced.

However, focusing on changes forced by the new administrative system can have no effect on the future if action is not taken. To achieve success in a democratic country it is necessary to exert influence on public opinion in the whole country as well as in local regions. The decisions of politicians depend on this. This situation creates new challenges for psychiatrists. Dialogue with insurance funds and local self-governing authorities should be carried out by a strong alliance, perhaps an association of psychiatric facilities. The creation of such an organisation and the beginning of a dialogue are urgently needed. The development of community-based psychiatry in Poland also depends on such actions. Paradoxically, it may be a cause for optimism that many issues in reforming the health care system in Poland are not yet finally settled.

\section{DIRECTIONS FOR RESEARCH}

One of the most important prerequisites for the successful implementation of reform is the systematic and continuous monitoring of the ongoing changes in the delivery of health services and research in promising areas. There is evidence that this may include studies of psychiatric morbidity and changing trends in this field, investigating links with differently structured and financed services and their accessibility for different population groups. Promising subjects are also the investigation of the impact of social disintegration and growing socio-economic differentiation on mental health disorders - particularly such phenomena as unemployment, homelessness, criminality, migration, xenophobia, the rapid increase in the aged population, and the growth of alcohol, drug and substance misuse, suicide and criminality, particularly in adolescents.

Research must also concentrate on studies of the effectiveness of different programmes of health promotion, and preventive medicine, and of the treatment, rehabilitation and integration into the community of chronically ill people of different ages, diagnoses and professions, counteracting discrimination and helping them to lead a life of adequate quality, satisfying their basic needs and guaranteeing their human rights. Naturally such studies do not exclude the necessity to continue the most important, though very costly, research based on the neurosciences and the development of new advanced technologies. This could also be an antidote to the predominance of the econometric and standardised model of thinking and practice in medicine aggressively promoted and enforced by bureaucratic and technocratic managers. Such a model might foster the development of two different health care systems for the poor and rich, disregarding human suffering and the necessity to alleviate it. This dangerous trend may be challenged by the existence of a value system shared by the majority of medical and psychiatric professionals.

Marek Balicki Head of Psychiatric Ward, Drewnica Psychiatric Hospital, Zabki, Warsaw; former First Deputy Minister of Health and Social Welfare (1992-1993)

Stefan Leder Professor of Medicine, Institute of Psychiatry and Neurology, Warsaw

Andrzej Piotrowski Professor of Medicine, Head of IV Department of Psychiatry, Institute of Psychiatry and Neurology, Warsaw 